University of Nebraska - Lincoln

DigitalCommons@University of Nebraska - Lincoln

Faculty Publications, Department of Psychology

Psychology, Department of

$2-2009$

\title{
Acquired Appetitive Responding to Intravenous Nicotine Reflects a Pavlovian Conditioned Association
}

Jennifer E. Murray

University of Nebraska-Lincoln, jem98@cam.ac.uk

Rick A. Bevins

University of Nebraska-Lincoln, rbevins1@unl.edu

Follow this and additional works at: https://digitalcommons.unl.edu/psychfacpub

Part of the Psychiatry and Psychology Commons

Murray, Jennifer E. and Bevins, Rick A., "Acquired Appetitive Responding to Intravenous Nicotine Reflects a Pavlovian Conditioned Association" (2009). Faculty Publications, Department of Psychology. 369.

https://digitalcommons.unl.edu/psychfacpub/369

This Article is brought to you for free and open access by the Psychology, Department of at DigitalCommons@University of Nebraska - Lincoln. It has been accepted for inclusion in Faculty Publications, Department of Psychology by an authorized administrator of DigitalCommons@University of Nebraska - Lincoln. 


\title{
Acquired Appetitive Responding to Intravenous Nicotine Reflects a Pavlovian Conditioned Association
}

\author{
Jennifer E. Murray and Rick A. Bevins \\ Department of Psychology, University of Nebraska-Lincoln
}

\begin{abstract}
Recent research examining Pavlovian appetitive conditioning has extended the associative properties of nicotine from the unconditioned stimulus or reward to include the role of a conditional stimulus (CS), capable of acquiring the ability to evoke a conditioned response. To date, published research has used presession extravascular injections to examine nicotine as a contextual CS in that appetitive Pavlovian drug discrimination task. Two studies in the current research examined whether a nicotine CS can function discretely, multiple times within a session using passive iv infusions. In Experiment 1, rats readily acquired a discrimination in conditioned responding between nicotine and saline infusions when nicotine was selectively paired with sucrose presentations. In Experiment 2, rats were either trained with nicotine paired with sucrose or explicitly unpaired with sucrose. The results showed that rats trained with explicitly unpaired nicotine and sucrose did not increase dipper entries after the infusions. Nicotine was required to be reliably paired with sucrose for control of conditioned responding to develop. Implications of these findings are discussed in relation to tobacco addiction, learning theory, and pharmacology.
\end{abstract}

Keywords: Pavlovian drug discrimination, appetitive conditioned response, IV nicotine, smoking essation, drug stimulus

Chronic nicotine use is a major public health crisis. According to the World Health Organization, there are nearly 1.2 billion current smokers worldwide, and more than 4.9 million of them die each year of tobacco-related diseases (Esson \& Leeder, 2004). Although the smoking rates have remained stable in developed countries, middle and low-income countries have seen a steady increase in smoking rates. In these countries where people can least afford the economic and health costs of tobacco use, families in poverty spend up to $15 \%$ of their disposable income on tobacco products rather than on food, education, or health care. The United Nations as part of the Millennium Development Goals established in 2000, made a call to reduce poverty and promote health and human development worldwide (General Assembly, 2000). Cessation of tobacco use is inextricably linked to these goals because of the dramatic costs of tobacco consumption and control.

One of the objectives of the United States government is to reduce smoking rates to less than 12\% of adults by 2010 (U.S. Department of Health \& Human Services, 2000). In 1997 there was a smoking prevalence of $24.7 \%$. By 2004 , this percentage had dropped to $20.9 \%$. However, in 2006 approximately $20.8 \%$ of adults were current smokers suggesting that the decline in smoking in the United States may be stalling in recent years (CDC, 2007). Perhaps contributing to this stall is the co-occurrence of a decrease in state-funded cessation programs and an increase in tobacco company expenditures targeted at maintaining the customer base (CDC, 2007). Regardless, if the people who do receive therapy have a greater likelihood of cessation success, the population of tobacco users will decline.
Among active smokers in the United States in 2000, approximately $70 \%$ wanted to quit using tobacco completely (CDC, 2002). Of these people, $41 \%$ stopped smoking for at least 1 full day during the preceding 12 months. Only $4.7 \%$ of smokers had maintained abstinence for 3 to 12 months. At this rate, the 2010 goal may be difficult to reach.

One way to reduce the prevalence of smoking is to improve the therapeutic techniques currently in practice. Improvements will come from diverse areas of research. These areas could inform therapies through studies concerning cultural factors, developmental effects, or genetic bases of vulnerability toward addiction. Learning theory informs another area of improvement. Indeed, a greater understanding of tobacco use based on Pavlovian conditioning has already enhanced behavioral therapy techniques. From this perspective, the unconditioned stimulus (US) effects, including the rewarding properties, of nicotine come to be associated with various nondrug stimuli that are repeatedly present during drug ingestion (Pavlov, 1927). These conditional stimuli (CSs) include environmental contexts as well as more proximal cues such as ashtrays and cigarettes. When tobacco users are later exposed to these CSs, the stimuli evoke drug-related physiological, behavioral, and subjective conditioned responses (CRs) that lead to craving and drug seeking (Bevins \& Palmatier, 2004; Conklin, 2006; Conklin \& Tiffany, 2001; Drummond, Tiffany, Glautier, \& Remington, 1995; Payne, Schare, Levis, \& Colletti, 1991; Poulos, Hinson, \& Siegel, 1981; Shiffman et al., 2002; for similar discussion with opioids and cocaine, see Childress, Hole, Ehrman, Robbins, McLellan, \&

The authors thank Chia Li, Jessica D. Linkugel, Rachel D. Penrod, Carmela M. Reichel, and Jamie L. Wilkinson for their assistance with surgeries. We also thank Steven B. Harrod for his thoughtful comments on an earlier version of this report. The research and Rick A. Bevins were supported by United States Public Health Service Grants DA018114. MED-PC programs used in the present article are available in a modified version upon request. Corresponding author - Rick A. Bevins, Department of Psychology, University of Nebraska-Lincoln, Lincoln, NE 68588-0308; email rbevins1@unl.edu. 
O'Brien, 1993). According to conditioning theory, repeated exposure to the CS without the nicotine US should decrease these drug-related CRs thus decreasing the likelihood of relapse (see Marlatt, 1990; Pavlov, 1927). Indeed, behavioral tobacco cessation therapies utilize cue exposure to help reduce the occurrence of craving in the presence of tobacco-related stimuli (see Conklin, 2006; Conklin \& Tiffany, 2002).

Conceptualizing nicotine as a potent US that enters into conditioned associations with situational stimuli has advanced our understanding of nicotine addiction processes and has improved smoking cessation efforts. However, a likely contributor to the tenacity of nicotine dependence is an extension of the associative properties of nicotine. This extension includes nicotine's interoceptive (subjective) stimulus, or CS, effects when reliably paired with another appetitive US (see Bevins \& Palmatier, 2004). There has been a wealth of research in humans, monkeys, and rats showing that nicotine has interoceptive discriminative stimulus effects (e.g., Clements, Glautier, Stolerman, White, \& Taylor, 1996; Morrison \& Stephenson, 1969; Takada, Hagen, Cook, Goldberg, \& Katz, 1988; for a review see Stolerman, 1999). Recently the pharmacological stimulus effects of nicotine have also been shown to serve as a contextual CS for a sucrose US in rats (Besheer, Palmatier, Metschke, \& Bevins, 2004; Bevins \& Palmatier, 2004; Bevins, Penrod, \& Reichel, 2007; Murray \& Bevins, 2007a, 2007b; Palmatier \& Bevins, 2007; Reichel, Linkugel, \& Bevins, 2007; Wilkinson, Murray, Li, Wiltgen, Penrod, Berg, \& Bevins, 2006). In that research, a subcutaneous (sc) injection of nicotine or saline was given before placement in a conditioning chamber. On nicotine sessions, liquid sucrose was delivered intermittently. On intermixed saline sessions sucrose was not available. Using head entries into the sucrose receptacle before the first sucrose delivery as a measure of conditioning (i.e., goal tracking; Boakes, 1977; Farwell \& Ayres, 1979), nicotine readily served as a CS as evidenced by increased dipper entries on nicotine compared to saline sessions. Indeed, we now know some about the behavioral processes (Besheer et al., 2004; Bevins et al., 2007; Murray \& Bevins, 2007b; Palmatier \& Bevins, 2007; Wilkinson et al., 2006) and some about the receptor systems (Murray \& Bevins, 2007a; Reichel et al., 2007) involved in the CS effects of nicotine.

While investigating various characteristics of the Pavlovian stimulus effects of nicotine, we have considered a variety of ways to extend that research to make the CS more similar to smoking in a human. Human smokers generally have a loading dose of nicotine in the mornings with frequent readministrations that maintain desired blood levels throughout the day (Benowitz, 1996; Russell, 1989). Each repeated nicotine intake temporarily lifts blood levels above baseline and is often accompanied by enhanced mood and increased cognitive function (Parrott \& Garnham, 1998; Parrott \& Kaye, 1999; Warburton \& Arnall, 1994). Indeed, these nicotine-induced enhancements can occur quite rapidly, after only a couple of puffs from a cigarette (Revell, 1988; Warburton \& Arnall, 1994), and may be reinforcing repeated self-administration in humans (Parrott, 2006). The animal models of human smoking that are considered to have more face validity use iv nicotine rather than extravascular injections because of the faster increase in brain nicotine levels (see Benowitz, 1996; Matta et al., 2007). Intravenous administration, like inhalation, is not subject to the same process of drug absorption that occurs as a result of an extravascular injection (Benowitz, Porchet, \& Jacob, 1990; Booze et al., 1999; Henningfield, Stapleton, Benowitz, Greyson, \& London, 1993). Indeed, iv infusions of 0.03 $\mathrm{mg} / \mathrm{kg}$ nicotine are common in rat models of nicotine self-administration (e.g., Corrigall \& Coen, 1989, 1991; Donny, Caggiula, Knopf, \& Brown, 1995; Donny, Caggiula, Mielke, Jacobs, Rose, \& Sved, 1998). In those studies, rats have an operant requirement (e.g., multiple presses on a predetermined lever) to complete before an infusion. Rats will increase pressing on the lever associated with nicotine infusions relative to an inactive lever, indicating that the nicotine infusions are serving as a reinforcer (LeSage, Keyler, Collins, \& Pentel, 2003; LeSage, Keyler, Shoeman, Raphael, Collins, \& Pentel, 2002; Palmatier et al., 2006; Rauhut, Dwoskin, \& Bardo, 2005; Rauhut, Mullins, Dwoskin, \& Bardo, 2002). Presumably, this low yet reinforcing dose of nicotine is perceptible. If so, we hypothesized that a nicotine infusion would also function as an interoceptive CS for appetitive stimuli that occur in close temporal proximity.

The current study sought to test this hypothesis by assessing whether brief iv infusions of nicotine could serve as CSs for sucrose. As part of this assessment, we eliminated alternative accounts of the $\mathrm{CR}$ by verifying that the nicotine infusions are controlling behavior. We also established that the nicotine CS is mediated by centrally localized nicotinic acetylcholine receptors (nAChRs). Finally, we determined that the CR is susceptible to extinction when sucrose is no longer delivered and to rapid reacquisition upon representation of the sucrose US. Indeed, the finding that iv nicotine functions as an appetitive CS in the present studies has opened up a wealth of future research directions.

\section{Experiment 1: Pavlovian Nicotine Discrimination}

For Experiment 1 we used a discrimination procedure similar to previous nicotine CS research with sc nicotine (e.g., Besheer et al., 2004). On a given training day, a rat received either nicotine administration paired with sucrose deliveries or saline administration with no sucrose deliveries. The key difference of interest in the current experiment is that nicotine and saline were administered iv, multiple times within each session, and each nicotine infusion was followed by a single sucrose delivery. If nicotine functions as a CS in this situation, we expect it will come to control a centrally mediated CR. We also expect that the $\mathrm{CR}$ will be susceptible to extinction like other CS types.

\section{Method}

\section{Subjects}

Sixteen male Sprague-Dawley rats (338 $\pm 4 \mathrm{~g}$ before start of study) were obtained from Harlan (Indianapolis, Indiana). Rats were housed individually in clear $48.3 \times 26.7 \times 20.3 \mathrm{~cm}(1$ $\times \mathrm{w} \times \mathrm{h}$ ) polycarbonate tubs lined with wood shavings. Water was continuously available in the home cage. Food (Harlan Teklad Rodent Diet) was restricted as described later. The colony was temperature and humidity controlled. All sessions were conducted during the light portion of a $12 \mathrm{hr}$ light: dark cycle. Protocols were approved by the University of Nebraska-Lincoln Animal Care and Use Committee and followed the "Guide for the Care and Use of Laboratory Animals" (National Research Council, 1996). 


\section{Apparatus}

Eight conditioning chambers (ENV-008CT; Med Associates, Inc., Georgia, VT) measuring $30.5 \times 24.1 \times 21.0 \mathrm{~cm}(1 \times \mathrm{w} \times \mathrm{h})$ were used in this experiment. Each chamber was enclosed in a light and sound attenuating polyvinyl chloride cubicle fitted with a fan to provide airflow and mask noise. A houselight with two bulbs $(28 \mathrm{~V}, 100 \mathrm{~mA})$ was mounted on the back wall of the cubicle. It was centered side-to-side, $23.5 \mathrm{~cm}$ above the top of the conditioning chamber, and $5 \mathrm{~cm}$ below the ceiling of the cubicle. Chamber sidewalls were aluminum; the ceiling and front and back walls were clear polycarbonate. Chambers were equipped with a recessed receptacle $(5.2 \times 5.2 \times 3.8 \mathrm{~cm} ; 1 \times$ $\mathrm{w} \times \mathrm{d}$ ) on the right sidewall. A dipper arm raised a 0.1-ml cup of $26 \%$ sucrose solution (wt/vol) into the receptacle. An infrared emitter/detector unit, $1.2 \mathrm{~cm}$ into the receptacle and $3 \mathrm{~cm}$ from the floor, monitored head entries into the dipper. A second infrared emitter/detector unit bisected the chamber 14.5 $\mathrm{cm}$ from the sidewall containing the receptacle and was positioned $4 \mathrm{~cm}$ above the rod floor. This unit provided a measure of chamber activity. Each chamber had a computer-controlled variable-speed syringe pump (Med-Associates, PMH-100VS) that allowed solutions (nicotine or saline) to be delivered iv. Pumps were located outside the sound-attenuating cubicle. A spring leash hanging into the chamber from a swivel attached to a movable arm located outside the chamber was secured to the catheter. Tygon tubing (AAQ04103; VWR, West Chester, PA) extended from a 5-ml syringe mounted on the syringe pump through the leash to attach to the catheter. A personal computer with Med Associates interface and software (MedPC for Windows, version IV) controlled infusions and sucrose deliveries and recorded dipper entries and chamber activity.

\section{Drugs}

(-)-Nicotine hydrogen tartrate, hexamethonium bromide, and mecamylamine hydrochloride were purchased from Sigma (St. Louis, MO) or Tocris Cookson, Inc. (Ellisville, MO). Nicotine was mixed in $0.9 \%$ sterile saline and was adjusted to a $\mathrm{pH}$ of $7.0 \pm 0.2$ using a dilute $\mathrm{NaOH}$ solution. Nicotine doses are reported in the base form; remaining drug doses are reported in salt form. Rats were assigned nicotine solutions based on their daily weights within a $20 \mathrm{~g}$ range. Nicotine was infused over 1 second at $0.03 \mathrm{mg} / \mathrm{kg} /$ infusion at a volume of $35.74 \mu 1$. Remaining drugs were mixed in $0.9 \%$ saline and injected sc at $1 \mathrm{ml} / \mathrm{kg}, 15$ minutes before testing.

\section{Preliminary Training}

Rats were handled for at least 3 minutes per day for 3 days. Food was removed after handling on the last day. Dipper training began the following day. A 50-min session was conducted on each of 3 consecutive days with the session not starting until a rat's first dipper entry. The probability of receiving sucrose decreased from 0.167 to 0.05 per 60 seconds over the three sessions (approximately 2.5 to 0.75 sucrose deliveries per minute). Rats received $20 \mathrm{~g}$ of food at the completion of the first two sessions; free access to food was returned following the third session.

\section{Surgical Procedures}

Surgical implantation of catheters occurred within 3 days of the last preliminary training session. Each rat was anesthe- tized with an intraperitoneal (ip) injection $(1 \mathrm{ml} / \mathrm{kg})$ of ketamine hydrochloride $(100 \mathrm{mg} / \mathrm{ml})$ followed by an ip injection $(0.6 \mathrm{ml} / \mathrm{kg})$ of xylazine hydrochloride $(20 \mathrm{mg} / \mathrm{ml})$ purchased from Midwest Veterinary Supply (Des Moines, IA). One end of a silastic catheter (CamCaths IVSA28, Ely, Cambridgeshire, U.K.) was implanted into the external left jugular vein. The other end was positioned under the skin such that it exited just below the scapulae via a backmount through which the catheter was able to be accessed by a metal cannula. Buprenorphine hydrochloride $(0.1 \mathrm{mg} / \mathrm{kg})$ was injected sc immediately after surgery. For the evening and full day after surgery, buprenorphine $(0.5 \mathrm{mg} / \mathrm{kg})$ was available in the drinking water to mange postsurgical pain. The catheter was flushed twice a day for the duration of the experiment with $0.2 \mathrm{ml}$ of sterile saline mixed with heparin (30 Units/ml; Midwest Veterinary Supply) except for the first five postsurgical flushes in which $0.1 \mathrm{ml}$ of sterile heparinized saline was mixed with streptokinase (ca. 8,000 Units/ml). Rats were allowed 5 days of recovery in their home cage with free access to food before the start of the experiments. Catheter patency was assessed with a 0.05 $\mathrm{ml}$ iv infusion of xylazine $(20 \mathrm{mg} / \mathrm{ml})$. This concentration produces clear motor ataxia within 5 seconds if the catheter is patent (cf. Bevins, 2005; Reichel, Linkugel, \& Bevins, 2008; Weeks, 1972). Only rats with patent catheters were included in analyses of each phase in both experiments.

\section{Training}

Acquisition. Rats had 2-hr sessions once daily in which they received 10 infusions. On nicotine sessions, 4-s access to sucrose was given 30 seconds after each infusion. Sucrose was withheld on saline sessions. To prevent rats from timing infusions, four different MedPC programs for each session type were created. The average time to the first infusion was 11 minutes with a range of 8 to 14 minutes; the average time between infusions was also 11 minutes with a range of 8 to 14 minutes. To allow comparable measurement between nicotine (i.e., sucrose) and saline (i.e., no sucrose) sessions, the program types were matched for timing of infusions. Session types and programs were randomly interspersed with the restriction that no more than two nicotine or two saline sessions occurred in a row. The houselights were on for 1 minute before each session; the light offset signaled the start of the session. The end of the session was also signaled by 1 minute of chamber illumination.

Testing. After acquiring the discrimination, rats entered testing cycles. On the first two consecutive days of each 3-day cycle, rats received one nicotine and one saline session as described earlier. If the rat met discrimination criteria, on Day 3 a test session occurred in place of a training session. To meet criteria, a rat had to have higher conditioned responding (i.e., elevation scores; see later) on at least 7 of the 10 trials within the nicotine session compared to the corresponding trials within the saline session. If a rat did not meet the criteria, it continued to the next pair of nicotine and saline sessions. There were four tests. Rats received a sc injection of $5 \mathrm{mg} / \mathrm{kg}$ hexamethonium, $1 \mathrm{mg} / \mathrm{kg}$ mecamylamine, or $0.9 \%$ saline 15 minutes before chamber placement in a random order. A final test with $0.5 \mathrm{mg} / \mathrm{kg}$ mecamylamine was added after rats completed the other three tests. Test sessions were the same as nicotine sessions described previously (i.e., 10 nicotine infusions followed 30 seconds later by sucrose). 
Extinction. Completion of the four test sessions was followed by another nicotine and saline training session. Rats $(n$ $=10$ ) then received repeated nicotine sessions with no sucrose deliveries. Sucrose was reintroduced for each rat after that rat's CR decreased by at least $50 \%$.

\section{Dependent Measures}

The primary dependent measure was an elevation score: the number of dipper entries during the 30 seconds after the infusion minus the number of dipper entries in the 30-s interval before the infusion. The elevation score is a common measure in related Pavlovian conditioning research (e.g., Morris \& Bouton, 2006; Murray, Li, Palmatier, \& Bevins, 2007; Palmatier \& Bevins, 2007; Simon \& Setlow, 2006). A positive value indicates more dipper entries during the CS; 0 indicates no change from the interval before the CS. We also measured total dipper entries to examine changes across sessions, and as an index of activity, the number of infrared beam breaks in the chamber was also measured.

\section{Data Analyses}

Acquisition of the discrimination was examined using twoway repeated measures factorial analyses of variance (ANO-
VAs) with Drug (nicotine vs. saline) as one factor and either Trial or Session (mean of the 10 trials) as the other factor. Responding on test sessions was examined using a one-way repeated measures ANOVA comparing Test Drug. Responding across trials within the test sessions was examined using a two-way repeated measures ANOVA with Test Drug as one factor and Trial as the other factor. Significant interactions were followed by pairwise comparisons using Fisher's Least Significant Difference (LSD) tests. Statistical significance was declared using a $p$-value less than .05 for all tests.

\section{Results}

\section{Acquisition}

Figure 1 shows that rats readily acquired the nicotine-saline discrimination. Using the measure of mean elevation scores shown in Figure 1A, there were significant main effects of Drug, $F(1,15)=113.85, p<.001$, and Session, $F(5,75)=25.49$, $p<.001$, and a significant Drug $\times$ Session interaction, $F(5,75)$ $=17.32, p<.001$, mean square error $(M S E)=2.70$. Elevation scores were higher on nicotine than saline for all sessions, LSDmimimum mean difference $(\mathrm{mmd})=1.16$. This pattern was also reflected across trials as shown in Figure 1B. There was a main effect

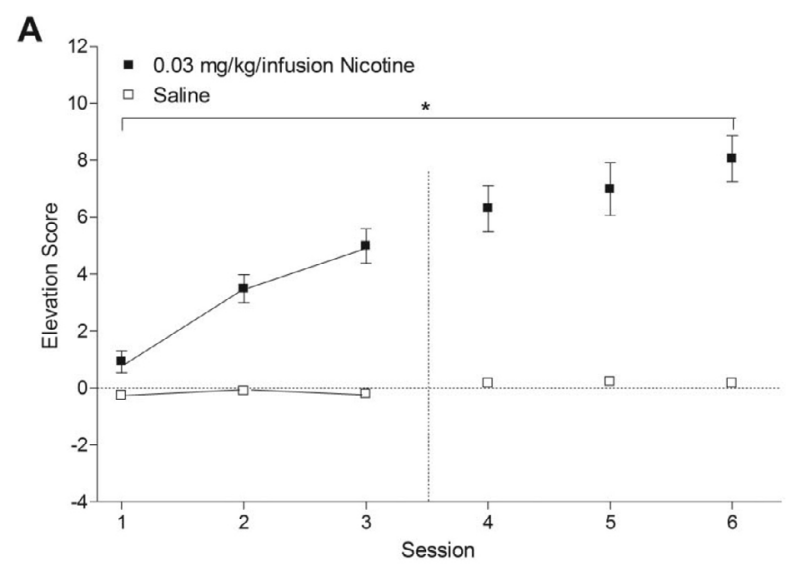

B


Figure 1. Panel A shows the mean elevation scores $( \pm 1$ SEM) of acquisition for nicotine and saline sessions of Experiment 1 . Panel B shows acquisition of the nicotine and saline discrimination ( +1 SEM) across each trial. Panel C shows mean total dipper entries $( \pm 1$ SEM) across each session for acquisition. Panel D shows mean chamber activity counts ( \pm 1 SEM) for each session. The vertical dashed line in Panels A, C, and D denote the start of testing. The dashed lines in Panel B separate the trials of each session. The asterisk denotes significant difference between nicotine and saline. 
of Drug, $F(1,15)=113.85, p<.001$, a main effect of Trial, $F(59$, $885)=8.34, p<.001$, and a Drug $\times$ Trial interaction, $F(59,885)=$ $6.19, p<.001, M S E=9.25$. Elevation scores were higher on nicotine than saline for Trials 7, 13 through 20, and 22 through 60, $\mathrm{LSD}_{\mathrm{mmd}}=2.11$. Importantly, the first trial within sessions was higher on nicotine than saline for Sessions 4 through 6 (i.e., Trials 31, 41, and 51) indicating that the interoceptive stimulus effects of nicotine and not the initial sucrose delivery served as the cue for session type. As goal tracking came under stimulus control, total dipper entries (Figure 1C) in the 2-hr nicotine sessions decreased. There were significant main effects of Drug, $F(1,15)=64.68, p<.001$, and Session, $F(5,75)=15.59, p<.001$, and a significant Drug $\times$ Session interaction, $F(5,75)=4.93, p=$ $.001, M S E=36039.32$. Total dipper entries were higher on nicotine than saline for Sessions 1 through 5, $\mathrm{LSD}_{\mathrm{mmd}}=134.24$; there was no difference on Session 6. For total chamber activity (Figure 1D), rats showed a general decrease in activity with repeated sessions. There was a main effect of Drug, $F(1,15)=$ 28.06, $p<.001$, indicating higher activity on nicotine than on saline. There was also a main effect of Session, $F(5,75)=5.33$, $p<.001, M S E=30192.77$, denoting more activity in general on Session 1 than on Sessions 4, 5, and 6, $\mathrm{LSD}_{\mathrm{mmd}}=86.88$, but no Drug $\times$ Session interaction, $F(5,75)=1.20, p=.319$.

\section{Testing}

Pretreatment with mecamylamine, but not hexamethonium, blocked conditioned responding evoked by the iv nicotine CS, $F(3,45)=17.15, p<.001, M S E=6.06$. Mean elevation scores (Figure 2A) were lower with 1 and $0.5 \mathrm{mg} / \mathrm{kg}$ mecamylamine pretreatment than saline pretreatment, $\mathrm{LSD}_{\mathrm{mmd}}=1.76$. Further examination showed this effect was consistent across trials (Figure 2B). There were main effects of Test Drug, $F(3$, $45)=17.15, p<.001$, and Trial, $F(9,135)=7.82, p<.001$, and a significant Test Drug $\times$ Trial interaction, $F(27,405)=1.81, p$ $=.009, M S E=12.89$. For Trials 2 through 9, elevation scores were lower after pretreatment with $1 \mathrm{mg} / \mathrm{kg}$ mecamylamine than pretreatment with saline, and for Trials 2 through 5 and 7 through 9, elevation scores were lower after pretreatment with $0.5 \mathrm{mg} / \mathrm{kg}$ mecamylamine than pretreatment with saline. There were higher elevation scores on Trials 3 and 6 for $5 \mathrm{mg} /$ $\mathrm{kg}$ hexamethonium pretreatment than saline pretreatment, LS$\mathrm{D}_{\mathrm{mmd}}=2.49$. There was no significant effect of Test Drug (Figure 2 C) on chamber activity, $F(3,45)=2.66, p=.06$.

\section{Extinction}

Removing sucrose deliveries from the nicotine sessions reduced the nicotine-evoked CR (see Figure 3). Elevation scores for the rats' first extinction session were lower than their last nicotine session before extinction, $t(9)=2.77, p=.022$. Responding further decreased between the first and last extinction sessions (range of 3-7 sessions), $t(9)=6.69, p<.001$. Responding recovered when sucrose was returned compared to responding on the last extinction session, $t(9)=4.04, p=.003$.

\section{Discussion}

The interoceptive effects of a low dose of iv nicotine functioned as a CS for an appetitive outcome as shown by the differential responding on nicotine compared to saline sessions. This discrimination cannot be explained by the first sucrose delivery of the nicotine sessions being an indicator that subsequent infusions will be followed by sucrose. That is, differential responding was evoked by the first infusion of each session later in training, indicating that iv nicotine was responsible for the CR.

\section{A}

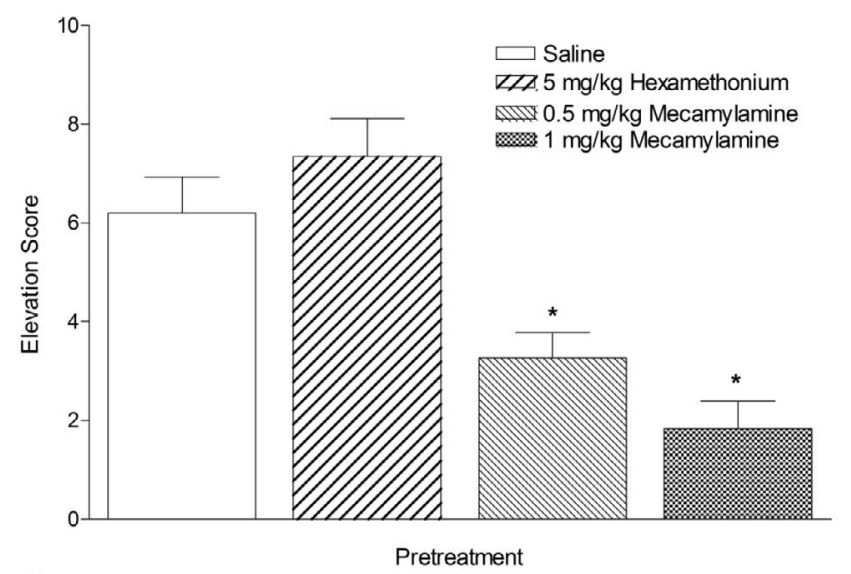

B
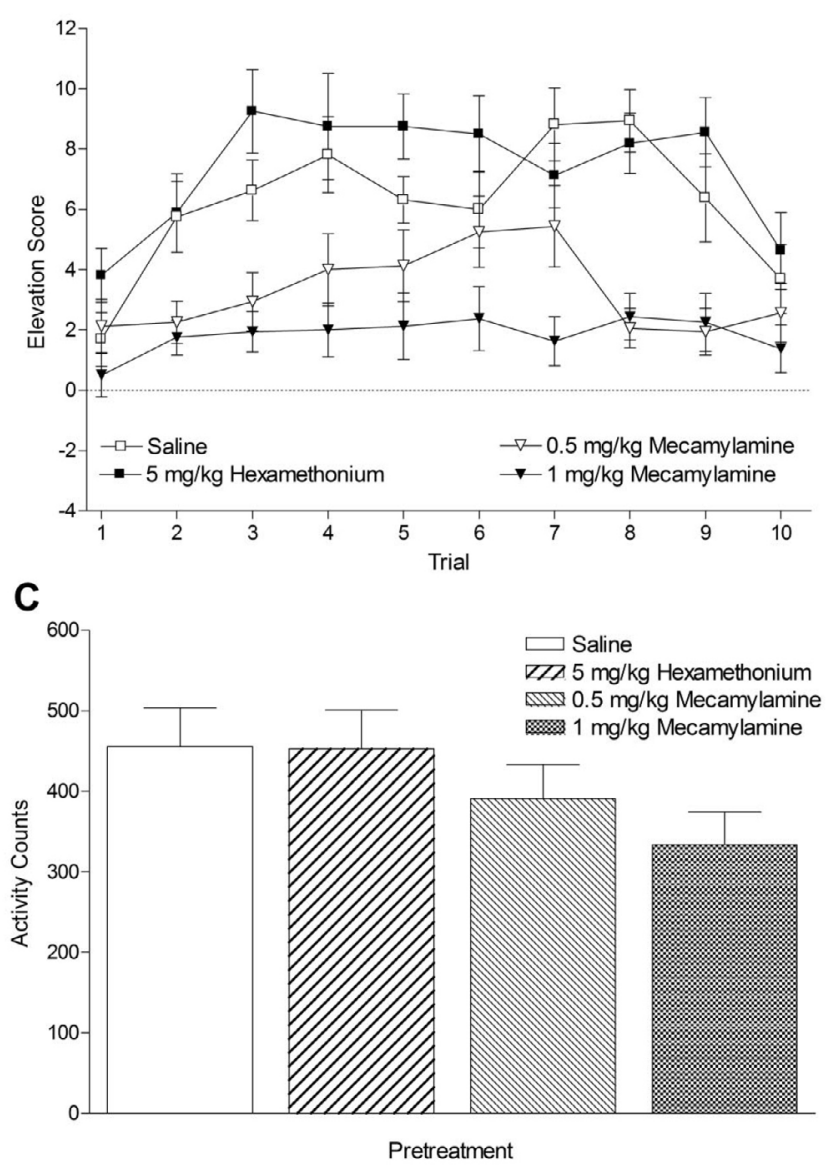

Figure 2. Panel A shows mean elevation scores ( +1 SEM) for the test sessions of Experiment 1. The asterisk denotes significant difference from saline pretreatment. Panel B shows mean elevation scores $( \pm 1$ SEM) for each trial of the test sessions. Significant differences from saline pretreatment are described in the text. Panel C shows mean $(+1$ SEM) total activity counts during test sessions. 


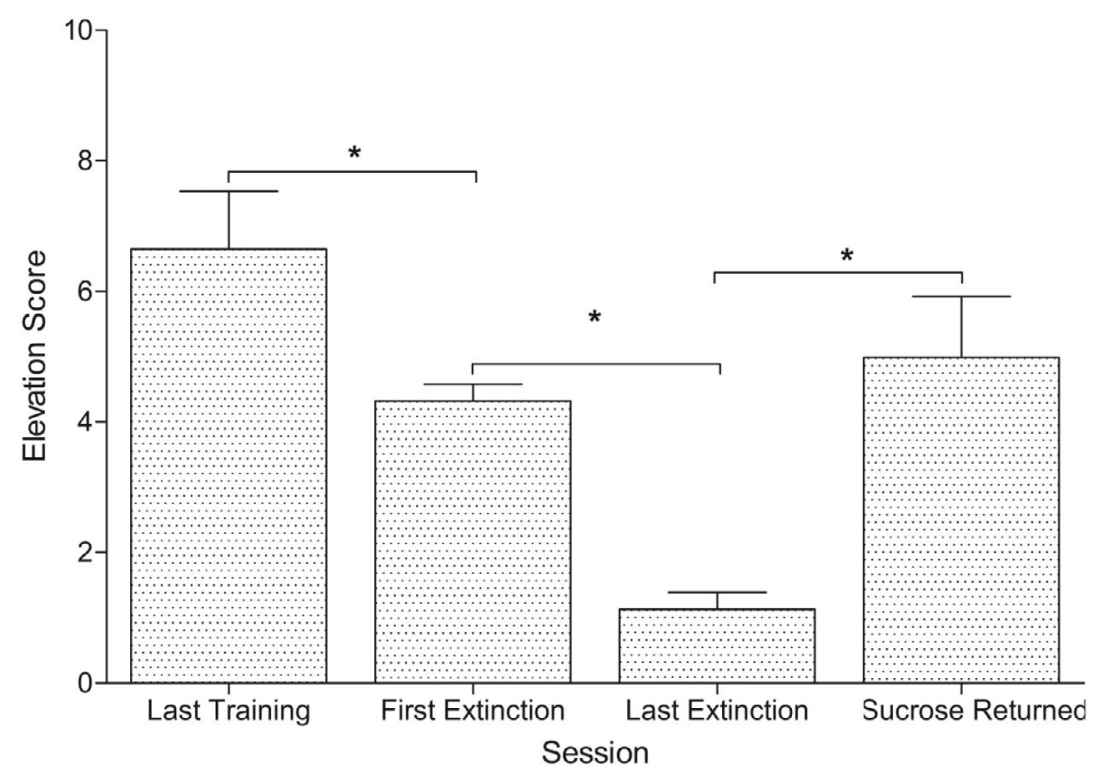

Figure 3. This figure shows mean elevation scores ( +1 SEM) for the first and last extinction sessions of Experiment 1 . The figure also shows the last nicotine training session before extinction and the sucrose session following extinction. The asterisk denotes significant difference between sessions.

Consistent with the previous studies that used an extravascular injection of nicotine as the CS (e.g., Besheer et al., 2004), the CS effects of nicotine infusions were centrally mediated. Hexamethonium, an nAChR antagonist that only weakly penetrates the blood-brain barrier (Asghar \& Roth, 1971), did not alter nicotine-evoked conditioned responding. Although only a single dose of hexamethonium was examined in the present study, this dose is often used for testing the central actions of nicotine (e.g., Besheer et al., 2004; Brazell et al., 1991; Loughlin et al., 2006; Stolerman et al., 1984). Mecamylamine, a nAChR antagonist that blocks both central and peripheral receptors (Papke, Sanberg, \& Shytle, 2001), blocked the CR relative to saline pretreatment throughout the entire session.

Blockade of conditioned responding by mecamylamine pretreatment also suggests that peripheral effects of the infusions are not sufficiently perceptible to control conditioned responding. If the infusion alone (i.e., not the nicotine) was perceptible, then responding would likely have increased across trials during test sessions because the sucrose presentations would have been signaled. It should be noted that saline pretreatment reduced the first elevation score of the test session compared to training levels. We attribute this effect to external inhibition of the injection procedure. Because an injection had never previously occurred before a training session, the CR was slightly inhibited when the change in procedure occurred (see Pavlov, 1927). Notably, the injection procedure was the same for all test drugs including saline, making the findings across the test sessions comparable.

Finally, there was a nonsignificant trend for a decrease in chamber activity with mecamylamine dose that coincided with a more robust and significant decrease in elevation scores (i.e., conditioned responding). This data pattern suggests a potential relation between the conditioned response and locomotor activity during the mecamylamine tests. To assess this possibility, we conducted a multiple regression analysis using Drug Dose (saline, 0.5 , and $1 \mathrm{mg} / \mathrm{kg}$ mecamylamine), Activity, and Rat Weight as the predictors for the Elevation Score. We in- cluded Weight as a predictor for two reasons. First, size of the rats might affect mobility in the in the chamber and hence alter dipper entries. Second, the size of the rat might affect absorption and distribution of mecamylamine or nicotine. Elevation scores were significantly predicted by the three-factor model, $r^{2}=.409, F(3,44)=10.14, p<.001$. There was a significant contribution of Drug Dose, $\beta=.54, p<.001$, but Activity and Weight did not contribute to the model, $\beta \mathrm{s} \leq .205, p \geq$ .102. This model indicates a preferential impact of mecamylamine, not activity or body weight, on nicotine-evoked conditioned responding.

Finally, when repeated nicotine sessions were given without sucrose (i.e., extinction) conditioned responding decreased. This result extends research using sc injections of nicotine as a contextual CS (Besheer et al., 2004; Murray \& Bevins, 2007b; Wilkinson et al., 2006) showing that the CR evoked by nicotine reflects a conditioned association between the iv nicotine infusion and the sucrose delivery. Indeed, an alternative account of the increased dipper entries with nicotine is that psychomotor stimulant effects of the nicotine somehow increased this behavior (e.g., Bevins \& Palmatier, 2003; Shoaib \& Stolerman, 1992). The reduction of the CR during extinction diminishes the feasibility of this account because nicotine is still being given in those sessions. In addition, reintroduction of sucrose after extinction resulted in reacquisition of the CR to nicotine in a single session. Taken together, these results support the conclusion that the interoceptive stimulus effects of iv nicotine were serving as an appetitive CS.

\section{Experiment 2: Importance of Temporal Contiguity}

Experiment 2 was designed to extend the conditions under which the CR is observed and to provide a control to assess nonassociative accounts of increased dipper entries in Experiment 1. As such, we trained one group with CS US pairings as described previously and another group with explicitly 
unpaired CS and US presentations (e.g., Servatius, Brennan, Beck, Beldowicz, \& Coyle-DiNorcia, 2001; Tiffany, Drobes, \& Cepeda-Benito, 1992). If dipper entries increased after nicotine infusions in the Unpaired group, it would suggest that nonassociative factors (see later) are responsible for the effects seen in Experiment 1.

\section{Method}

\section{Subjects, Apparatus, and Drugs}

Fifteen male Sprague-Dawley rats ( $333 \pm 2 \mathrm{~g}$ before start of study) were housed and maintained as described earlier. The apparatus was unchanged, and nicotine was prepared and administered as described in Experiment 1.

\section{Preliminary Training and Surgical Procedures}

Rats were given the same preliminary training, surgical implantation of catheters, and recovery as described in Experiment 1.

\section{Training}

Acquisition. Rats were assigned to either the Paired group or the Unpaired group irrespective of preliminary training performance. Rats in the Paired group $(n=7)$ received 10 nicotine infusions followed 30 seconds later with 4-s access to sucrose. The average time to the first infusion was 11 minutes with a range of 8 to 14 minutes; the average time between infusions was also 11 minutes with a range of 8 to 14 minutes (cf. nicotine sessions of Experiment 1). Rats assigned to the Unpaired group $(n=8)$ received nicotine infusions explicitly unpaired with sucrose deliveries. The timing of infusions was identical to the Paired group. Sucrose deliveries were temporally spaced at least 4 minutes from nicotine infusions. Acquisition training continued for seven sessions.

Extinction. After acquisition, sucrose presentations were withheld for 11 consecutive sessions (i.e., extinction). Nicotine infusions were continued as described in acquisition.

\section{Dependent Measures and Data Analyses}

Dipper entries and activity were measured as described for Experiment 1. Acquisition and extinction were examined using two-way mixed Groups ANOVAs with Group (Paired vs. Unpaired) as the between-subjects factor and Trial or Session (mean of the 10 trials) as the within-subjects factor. Significant interactions were followed by pairwise comparisons using Fisher's LSD tests. Statistical significance was declared using a $p$-value less than .05 for all tests.

\section{Results}

\section{Acquisition}

Figure 4A shows that the Paired group acquired a nicotinespecific CR; the Unpaired group did not selectively respond in the 30-s after the nicotine infusions. There were main effects of Group, $F(1,13)=114.61, p<.001$, and Session, $F(6,78)=5.17$, $p<.001$, and a significant Group $\times$ Session interaction, $F(6,78)$ $=2.68, p=.020, M S E=5.45$. Elevation scores were higher on all sessions for the Paired group compared to the Unpaired group, $\mathrm{LSD}_{\mathrm{mmd}}=2.41$. The same pattern was reflected across trials (Figure 4B). There was a main effect of Group, $F(1,13)=$ $109.19, p<.001$, and of Trial, $F(69,897)=50.24, p<.001$, but no Group $\times$ Trial interaction, $F(69,897)=1.15, p=.193$. Elevation scores by trial were higher for the Paired group than the Unpaired group, $M s=5.87 \pm 0.469$ and $-0.83 \pm 0.438$, respectively. Similar to Experiment 1, total dipper entries (Figure 4C) decreased as goal tracking came under stimulus control. The Paired group also had more total dipper entries than the Unpaired group. There were main effects of Group, $F(1$, 13) $=6.54, p=.024$, and Session, $F(6,78)=13.85, p<.001$, but no Group $\times$ Session interaction, $F(6,78)=1.13, p=.351$. There was no difference between groups on chamber activity (Figure $4 \mathrm{D}), F s \leq 2.18, p s \geq .054$.

\section{Extinction}

Figure 5A shows that removal of sucrose deliveries reduced the $C R$ in the Paired group to the level of the Unpaired group. There were main effects of Group, $F(1,12)=48.69, p<.001$, and Session, $F(10,120)=8.84, p<.001$, and a significant Group $\times$ Session interaction, $F(10,120)=8.58, p<.001, M S E=0.79$. The Paired group had higher elevation scores than the Unpaired group on extinction Sessions 1 through 6 and 8 through $10, \mathrm{LSD}_{\mathrm{mmd}}=0.94$. This pattern was also shown across trials (Figure 5B). There were main effects of Group, $F(1,12)=48.69$, $p<.01$, and Trial, $F(109,1308)=2.00, p<.05$, and a significant Group $\times$ Trial interaction, $F(109,1308)=1.93, p<.05$, MSE $=7.86$. The Paired group had higher elevation scores than the Unpaired group for extinction Trials 1-14, 18, 24-27, 29, 32$33,35-36,38-39,42,51,58,79,86,93$, and $102, \mathrm{LSD}_{\mathrm{mmd}}=2.94$. There was no difference between groups for total dipper entries (Figure 5C), Fs $\leq 1.36, p s \geq .207$, or chamber activity (Figure $5 \mathrm{D}), F s \leq 1.49, p s \geq .152$.

\section{Discussion}

Only rats in the Paired group showed increased dipper entries immediately following nicotine infusions, indicating the importance of contiguity between the CS and US in acquisition of conditioned responding. Although the Unpaired group received equal nicotine presentations and sucrose deliveries, they were not temporally contiguous, and rats did not develop the $\mathrm{CR}$. These findings from the Unpaired group eliminate nonassociative accounts of the increased goal tracking seen in Experiment 1 and in the Paired group of this experiment. One nonassociative property of nicotine that has received a lot of recent attention is its reward-enhancing effects (e.g., Chaudhri et al., 2006, 2007; Donny et al., 2003; Olausson, Jentsch, \& Taylor, 2003; Palmatier et al., 2006). In the current task, repeated sucrose presentations may be imbuing the goal receptacle with conditioned appetitive properties. If nicotine is responsible for enhancing the salience or appetitive quality of the goal receptacle, then each infusion would be followed by an increase in dipper entries. Because the groups received equal amounts of sucrose, goal receptacle quality would be enhanced to an equivalent degree, and elevation scores would have been similar in the two groups. This explanation, however, requires that rats in the Unpaired group access the sucrose so the goal receptacle acquires those similar appetitive properties. Elimination of such an account assumes that associative properties of nicotine are evoking the increase in dipper entries. We verified 
A
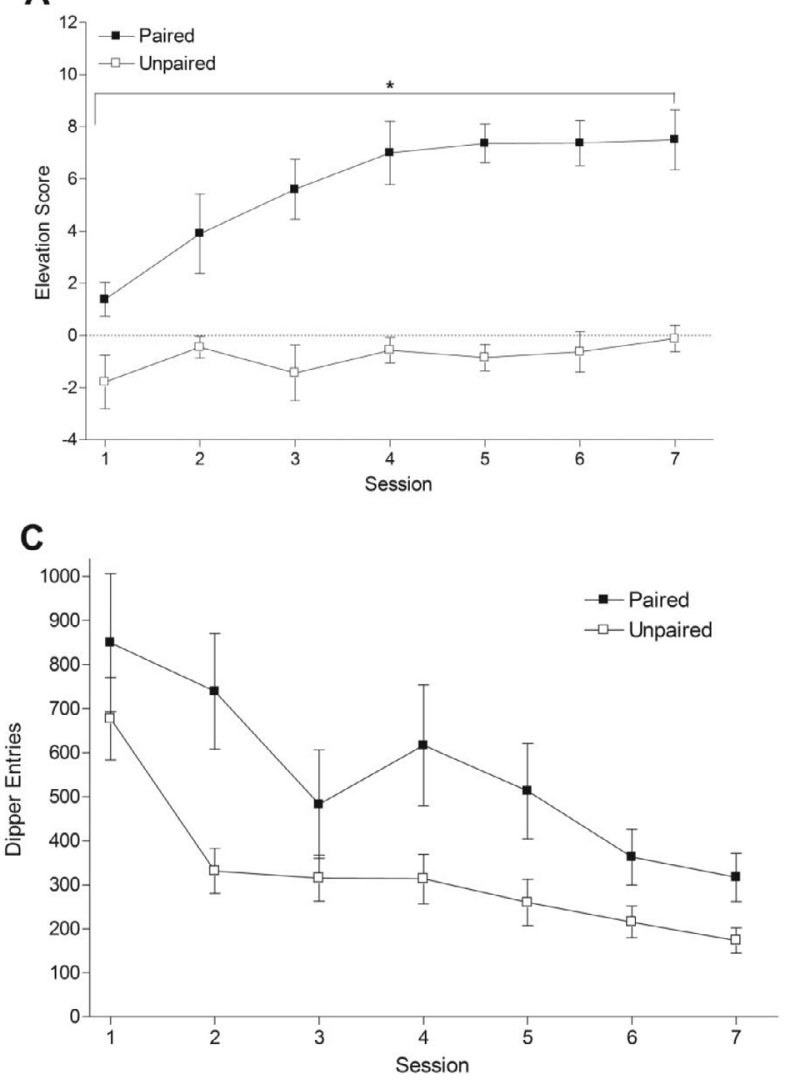

B

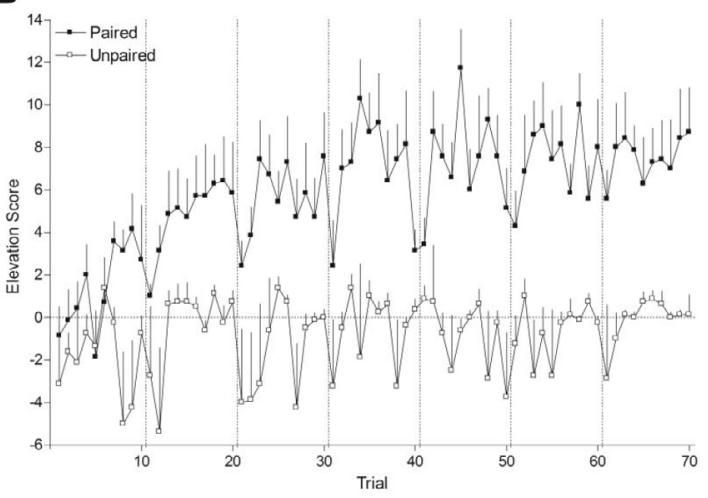

D

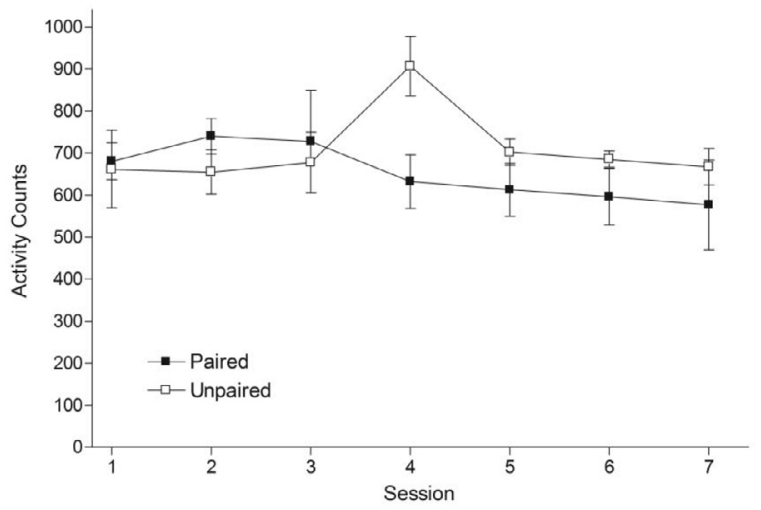

Figure 4. Panel A shows mean elevation scores ( \pm 1 SEM) of each session of acquisition for Paired and Unpaired groups of Experiment 2. Panel B shows elevation scores ( +1 SEM) across trials. Panel C shows mean total dipper entries ( \pm 1 SEM) across each session. Panel D shows mean chamber activity counts ( \pm 1 SEM) for each session. The vertical dashed lines in Panel B separate the trials of each session. The asterisk denotes significant difference between Paired and Unpaired groups.

that rats were engaged in at least one dipper entry during each 4-s sucrose presentation. The Paired group retrieved $91.2 \%$ of their deliveries, and the Unpaired group retrieved $90.5 \%$ of their sucrose deliveries, confirming that conditioned appetitive properties of the goal receptacle were not driving dipper entries after nicotine infusions.

Finally, similar to Experiment 1, repeated nicotine presentations without sucrose resulted in a gradual decrease in conditioned responding across sessions in the Paired group. This decrease continued until it reached the response level of the Unpaired group. There was no change in dipper entries for the Unpaired group. Combined, these data support that the conditioned responding reflects a CS $\cdot \mathrm{US}$ association.

\section{General Discussion}

The results of the two experiments in this report are consistent with the notion that the central nervous system (CNS) effects of a low dose of iv nicotine function as an appetitive CS. Nicotine is well-known to have profound effects in the periphery such as muscle control (e.g., Lembeck, 1999), vasodilation (e.g., Eguchi, Miyashita, Kitamura, \& Kawasaki, 2007), and anti-inflammatory enhancement (e.g., Ulloa, 2005). However, blockade of peripheral nAChRs with hexamethonium did not alter the CR, whereas blockade of central and peripheral nAChRs blocked the CR, leaving the CNS to selec- tively mediate the nicotine CS. Notably, the present research also demonstrates a host of phenomena widely studied in more traditional Pavlovian conditioning tasks with discrete exteroceptive stimuli. This list includes an increase in conditioned responding with an increased number of trials (e.g., Kalish, 1954) and the importance of temporal contiguity (e.g., Murphy \& Baker, 2004) during acquisition. In addition, there is a loss of conditioned responding with removal of the US (e.g., Ayres \& DeCosta, 1971) followed by fast reacquisition of the CR upon US representation (e.g., Tomie, Hayden, \& Biehl, 1980).

Indeed, even the striking pattern of within-session conditioned responding during acquisition fits within a framework of learning theory. Early session infusions controlled lower levels of responding than infusions later in the session, followed by a downturn toward the end of the session. This inverted-U pattern of conditioned responding within sessions is similar to those studied in both Pavlovian and operant conditioning tasks (e.g., McSweeney, 1992; Servatious et al., 2001). A dual process theory of responding has been used to explain this pattern (see Groves \& Thompson, 1970; McSweeney \& Hinson, 1992). That account suggests that the first part of the pattern, the lower responding in the early portion of the acquisition sessions followed by increases across trials, may be the result of a response sensitization effect of the CS US association. That is, repeated presentations of the stimuli enhance 

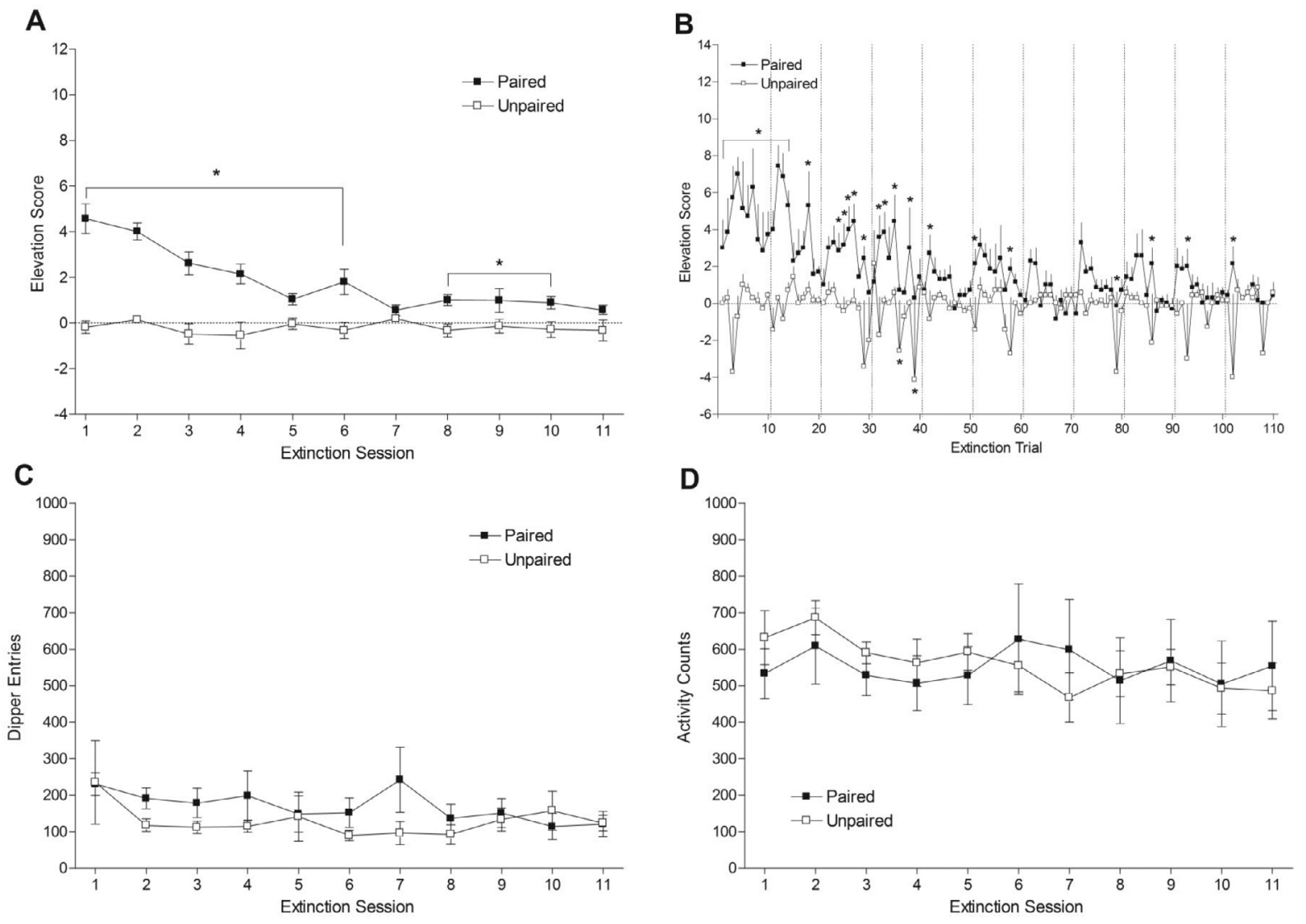

Figure 5. Panel A shows mean elevation scores $( \pm 1$ SEM) of each session of extinction for Paired and Unpaired groups of Experiment 2. Panel B shows elevation scores ( +1 SEM) across trials. Panel C shows mean total dipper entries ( \pm 1 SEM) across each session. Panel D shows mean chamber activity counts $( \pm 1$ SEM) for each session. The vertical dashed lines in Panel B separate the trials of each session. The asterisk denotes significant difference between Paired and Unpaired groups.

responsiveness. For example, in a study of the mouthing response to food in rat pups, initial presentations resulted in increased rates of responding (Swithers-Mulvey \& Hall, 1992; see also McSweeney \& Swindell, 1999). Similarly, in an operant task in which rats were trained to leverpress for food pellets there was an initial increase in response rates in the early portion of the sessions (McSweeney, 1992; see also McSweeney, Hinson, \& Cannon, 1996).

The response rates in both types of studies reached a peak level, and then declined. Similarly, in the current research the decrease in responding on the later trials may be an effect of CS US habituation because of decreased strength of the motivated goal-tracking behavior after repeated contact with the sucrose goal (McSweeney \& Swindell, 1999). Alternatively, the later trial responding can be explained pharmacologically. As each successive infusion accumulates into the background brain nicotine level during the session, the perceptible change brought about by each infusion may be decreasing, resulting in decreased responding. This account, however, cannot explain the response pattern of early trials. After 22 hours since finishing the previous session, brain nicotine levels in the rats would be nearly nothing. Therefore, the first several infusions should be highly perceptible and hence evoke a strong CR. Interestingly, the different subtypes of $\mathrm{nAChRs}$ responsible for the behavioral effects of nicotine differentially respond to nicotine administration (e.g., McGehee, Heath, Gelber, Devay, \&
Role, 1995; Pidoplichko, DeBiasi, Williams, \& Dani, 1997) and may help explain the response pattern in early trials. After activation, some receptors are desensitized to further effects of nicotine much more readily than others (e.g., Fenster, Rains, Noerager, Quick, \& Lester, 1997; Wooltorton, Pidoplichko, Broide, \& Dani, 2003). The effects of those receptors that experience prolonged desensitization following activation may predominate during the first couple infusions; however, those effects would not be available for conditioning in later trials. Perhaps the CR in the current research is selectively mediated by receptors that do not remain in a desensitized state during chronic nicotine exposure. Of course, more research will be required to determine the actual processes responsible for the pattern of conditioned responding.

Upon examination of the extinction across trials, a second series of intriguing within-session patterns is visible in the Paired group. There is an initial burst in conditioned responding early in sessions that drops off in later parts of the sessions. These early session increases might reflect spontaneous recovery of the CR (Bouton, 1993; Pavlov, 1927; Rescorla, 1997, 2004). The subsequent responding within each session then gradually tapers off across trials when the US does not appear. Between sessions, the degree of this apparent spontaneous recovery gradually diminishes with continued CS alone exposure. Notably, spontaneous recovery is regarded as one of the 'threats to extinction' of drug use (see Conklin \& Tif- 
fany, 2002). Therefore, spontaneous recovery of a CR evoked by a nicotine CS may also contribute to tobacco addiction.

Perhaps the most exciting aspects of the present research are the empirical and theoretical advances for future studies. For example, having a single nicotine infusion paired with a single sucrose delivery permits trial-by-trial measures of the nicotine CS-US association. How responding changes across a session and manipulations of the intertrial and interstimulus intervals could offer a clearer picture of the associability of the infusions. Within-session manipulations would also be possible, allowing examinations of higher-order associations such as the addition of positive or negative features that indicate when the nicotine sucrose association is active. Because iv nicotine is used in animal models of self-administration, and because the iv route of administration is generally considered to have more face validity than extravascular routes of administration (see Benowitz, 1990; Matta et al., 2007), we can also better examine the possibility that a stimulus such as nicotine may be able to serve multiple roles at the same time (i.e., as a reinforcer and as a CS). The ability of nicotine to "multitask" has been shown by Caggiula and colleagues who have demonstrated that nicotine can be a primary reinforcer while simultaneously enhancing the reinforcing effects of other stimuli (e.g., Chaudhri et al., 2006, 2007; Palmatier et al., 2006). As such, it is of interest to determine whether the CS effects of nicotine can modify the rate of iv nicotine self-administration when the CS properties are manipulated. If so, these multifaceted characteristics of nicotine can be incorporated into models of tobacco dependence and relapse. It may be the case that the limited efficacy of behavioral therapy as a smoking cessation technique could be because of the need to consider this CS property of nicotine along with other aspects of the individual's learning history. These therapies rely on repeated, nonreinforced exposure of drug-related stimuli (see Conklin, 2006; Conklin \& Tiffany, 2002). If the stimulus properties of nicotine are capable of forming compound CSs with the environmental stimuli that are extinguished during cue-exposure therapy, it may be a step in explaining the partial effectiveness of these therapies. Using iv nicotine as a CS would relatively easily allow for examination of cue competition between nicotine and other stimuli. Overall, this research could significantly enhance our understanding of how the nicotine in tobacco may modulate behavior, and subsequently enhance the success of cessation treatments.

\section{References}

Asghar, K., \& Roth, L. J. (1971). Entry and distribution of hexamethonium in the central nervous system. Biochemical Pharmacology, 20, 2787-2795.

Ayers, J. J. B., \& DeCosta, M. J. (1971). The truly random control as an extinction procedure. Psychonomic Science, 24, 31-33.

Benowitz, N. L. (1990). Pharmacokinetic considerations in understanding nicotine dependence. In: G.Bock, J.Marsh, (Eds.), The biology of nicotine dependence (pp. 186-209). Chichester, New York: Wiley.

Benowitz, N. L. (1996). Pharmacology of nicotine: Addiction and therapeutics. Annual Review of Pharmacology and Toxicology, 36, 597-613.

Benowitz, N. L., Porchet, H., Jacob, P. (1990). Pharmacokinetics, metabolism, and pharmacodynamics of nicotine. In: S.Wonnacott, M. A. H.Russell, \& I. P.Stolerman, (Eds.), Nicotine psychopharmacology: Molecular, cellular, and behavioural aspects (pp. 112-157). Oxford: Oxford University Press.

Besheer, J., Palmatier, M. I., Metschke, D. M., \& Bevins, R. A. (2004). Nicotine as a signal for the presence or absence of sucrose reward: A Pavlovian drug appetitive conditioning preparation in rats. Psychopharmacology, 172, 108-117.

Bevins, R. A. (2005). The reference-dose place conditioning procedure yields a graded dose-effect function. International Journal of Comparative Psychology, 18, 101-111.

Bevins, R. A., \& Palmatier, M. I. (2003). Nicotine-conditioned locomotor sensitization in rats: Assessment of the US-preexposure effect. Behavioural Brain Research, 14, 365-374.

Bevins, R. A., \& Palmatier, M. I. (2004). Extending the role of associative learning processes in nicotine addiction. Behavioral and Cognitive Neuroscience Reviews, 3, 143-158.

Bevins, R. A., Penrod, R. D., \& Reichel, C. M. (2007). Nicotine does not produce state-dependent effects on learning in a Pavlovian appetitive goal-tracking task in rats. Behavioural Brain Research, 177, 134-141.

Boakes, R. A. (1977). Performance on learning to associate a stimulus with positive reinforcement. In: H.Davis, \& H. M. B.Hurwitz, (Eds.), Operant-Pavlovian interactions (pp. 67-97). New Jersey: Erlbaum.

Booze, R. M., Welch, M. A., Wood, M. L., Billings, K. A., Apple, S. R., \& Mactutus, C. F. (1999). Behavioral sensitization following repeated intravenous nicotine administration: Gender differences and gonadal hormones. Pharmacology, Biochemistry and Behavior, 64, 827-839.

Bouton, M. E. (1993). Context, time, and memory retrieval in the interference paradigms of Pavlovian learning. Psychological Bulletin, 114, 80-99.

Brazell, M. P., Mitchell, S. N., \& Gray, J. A. (1991). Effect of acute administration of nicotine on in vivo release of noradrenaline in the hippocampus of freely moving rats: A dose-response and antagonist study. Neuropharmacology, 30, 823-833.

CDC. (2002). Cigarette smoking among adults-United States, 2000. $M M W R, 51,642-645$.

CDC. (2007). Cigarette smoking among adults - United States, 2006. MMWR, 56, 1157-1161.

Chaudhri, N., Caggiula, A. R., Donny, E. C., Booth, S., Gharib, M., Craven, L., et al. (2006). Operant responding for conditioned and unconditioned reinforcers in rats is differentially enhanced by the primary reinforcing and reinforcement-enhancing effects of nicotine. Psychopharmacology, 189, 27-36.

Chaudhri, N., Caggiula, A. R., Donny, E. C., Booth, S., Gharib, M., Craven, L., et al. (2007). Self-administered and noncontingent nicotine enhance reinforced operant responding in rats: Impact of nicotine dose and reinforcement schedule. Psychopharmacology, 190, 353-362.

Childress, A. R., Hole, A. V., Ehrman, R. N., Robbins, S. J., McLellan, A. T., \& O'Brien, C. P. (1993). Cue reactivity and cue reactivity interventions in drug dependence. NIDA Research Monograph, 137, 73-95.

Clements, K., Glautier, S., Stolerman, I. P., White, J-A. W., \& Taylor, C. (1996). Classical conditioning in humans: Nicotine as CS and alcohol as US. Human Psychopharmacology, 11, 85-95.

Conklin, C. A. (2006). Environments as cues to smoke: Implications for human extinction-based research and treatment. Experimental and Clinical Psychopharmacology, 14, 12-19.

Conklin, C. A., \& Tiffany, S. T. (2001). The impact of imagining personalized versus standardized urge scenarios on cigarette 
craving and autonomic reactivity. Experimental and Clinical Psychopharmacology, 9, 399-408.

Conklin, C. A., \& Tiffany, S. T. (2002). Applying extinction research and theory to cue-exposure addiction treatments. Addiction, 97, 155-167.

Corrigall, W. A., \& Coen, K. M. (1989). Nicotine maintains robust self-administration in rats on a limited-access schedule. Psychopharmacology, 99, 473-478.

Corrigall, W. A., \& Coen, K. M. (1991). Selective dopamine antagonists reduce nicotine self-administration. Psychopharmacology, 104, 171-176.

Donny, E. C., Caggiula, A. R., Knopf, S., \& Brown, C. (1995). Nicotine self-administration in rats. Psychopharmacology, 122, 390-394.

Donny, E. C., Caggiula, A. R., Mielke, M. M., Jacobs, K. S., Rose, C., \& Sved, A. F. (1998). Acquisition of nicotine self-administration in rats: The effects of dose, feeding schedule, and drug contingency. Psychopharmacology, 136, 83-90.

Donny, E. C., Chaudhri, N., Caggiula, A. R., Evans-Martin, F. F., Booth, S., Gharib, M. A., et al. (2003). Operant responding for a visual reinforcer in rats is enhanced by noncontingent nicotine: Implications for nicotine self-administration and reinforcement. Psychopharmacology, 169, 68-76.

Drummond, D. C., Tiffany, S. T., Glautier, S., \& Remington, B. (1995). Cue exposure in understanding and treating addictive behaviours. In: D. C.Drummond, S. T.Tiffany, S.Glautier, \& B.Remington, (Eds.), Addictive behavior: Cue exposure theory and practice. (pp. 1-17). Oxford: Wiley.

Eguchi, S., Miyashita, S., Kitamura, Y., \& Kawasaki, H. (2007). Alpha3beta4-nicotinic receptors mediate adrenergic nerve- and peptidergic (CGRP) nerve-dependent vasodilation induced by nicotine in rat mesenteric arteries. British Journal of Pharmacology, 151, 1216-1223.

Esson, C. M., \& Leeder, S. R. (2004). The millennium development goals and tobacco control: An opportunity for global partnership. France: World Health Organization.

Farwell, B. J., \& Ayres, J. J. B. (1979). Stimulus-reinforcer and response-reinforcer relations in the control of conditioned appetitive headpoking ("goal-tracking") in rats. Learning and Motivation, 10, 295-312.

Fenster, C. P., Rains, M. F., Noerager, B., Quick, M. W., \& Lester, R. A. J. (1997). Influence of subunit composition on desensitization of neuronal acetylcholine receptors at low concentrations of nicotine. The Journal of Neuroscience, 17, 5747-5759.

General Assembly, (2000). United Nations millennium declaration. Resolution 55/2. Retrieved February 21, 2008, from http:// www.un.org/millennium/declaration/ares552e.pdf

Groves, P. M., \& Thompson, R. F. (1970). Habituation: A dual-process theory. Psychological Review, 77, 419-450.

Henningfield, J. E., Stapleton, J. M., Benowitz, N. L., Grayson, R. F., \& London, E. D. (1993). Higher levels of nicotine in arterial than in venous blood after cigarette smoking. Drug and Alcohol Dependence, 33, 23-29.

Kalish, H. I. (1954). Strength of fear as a function of the number of acquisition and extinction trials. Journal of Experimental Psychology, 47, 1-9.

Lembeck, F. (1999). Epibatidine: High potency and broad spectrum activity on neuronal and neuromuscular nicotinic acetylcholine receptors. Naunyn-Schmiedeberg's Archives of Pharmacology, 359, 378-385.
LeSage, M. G., Keyler, D. E., Collins, G., \& Pentel, P. R. (2003). Effects of continuous nicotine infusion on nicotine self-administration in rats: Relationship between continuously infused and self-administered nicotine doses and serum concentrations. Psychopharmacology, 170, 278-286.

LeSage, M. G., Keyler, D. E., Shoeman, D., Raphael, D., Collins, G., \& Pentel, P. R. (2002). Continuous nicotine infusion reduces nicotine self-administration in rats with $23-\mathrm{h} /$ day access to nicotine. Pharmacology, Biochemistry, \& Behavior, 72, 279-289.

Loughlin, S. E., Islas, M. I., Cheng, M. Y., Lee, A. G., Villegier, A. S., \& Leslie, F. M. (2006). Nicotine modulation of stress-related peptide neurons. The Journal of Comparative Neurology, 497, 575-588.

Marlatt, G. A. (1990). Cue exposure and relapse prevention in the treatment of addictive behaviors. Addictive Behaviors, 15, 395-399.

Matta, S. G., Balfour, D. J., Benowitz, N. L., Boyd, R. T., Buccafusco, J. J., Caggiula, A. R., et al. (2007). Guidelines on nicotine dose selection for in vivo research. Psychopharmacology, 190, 269-319.

McGehee, D. S., Heath, M. J. S., Gelber, S., Devay, P., \& Role, L. W. (1995). Nicotine enhancement of fast excitatory synaptic transmission in CNS by presynaptic receptors. Science, 269, 1692-1696.

McSweeney, F. K. (1992). Rate of reinforcement and session duration as determinants of within-session patterns of responding. Animal Learning \& Behavior, 20, 160-169.

McSweeney, F. K., \& Hinson, J. M. (1992). Patterns of responding within sessions. Journal of the Experimental Analysis of Behavior, 58, 19-36.

McSweeney, F. K., Hinson, J. M., \& Cannon, C. B. (1996). Sensitization-habituation may occur during operant conditioning. Psychological Bulletin, 120, 256-271.

McSweeney, F. K., \& Swindell, S. (1999). General-process theories of motivation revisited: The role of habituation. Psychological Bulletin, 125, 437-457.

Morris, W. R., \& Bouton, M. E. (2006). Effect of unconditioned stimulus magnitude on the emergence of conditioned responding. Journal of Experimental Psychology: Animal Behavior Processes, 32, 371-385.

Morrison, C. F., \& Stephenson, J. A. (1969). Nicotine injections as the conditioned stimulus in discrimination learning. Psychopharmacologia, 15, 351-360.

Murphy, R. A., \& Baker, A. G. (2004). A role for CS-US contingency in Pavlovian conditioning. Journal of Experimental Psychology: Animal Behavior Processes, 30, 229-239.

Murray, J. E., \& Bevins, R. A. (2007a). Behavioral and neuropharmacological characterization of nicotine as a conditional stimulus. European Journal of Pharmacology, 561, 91-104.

Murray, J. E., \& Bevins, R. A. (2007b). The conditional stimulus effects of nicotine vary as a function of training dose. Behavioural Pharmacology, 18(8), 707-716.

Murray, J. E., Li, C., Palmatier, M. I., \& Bevins, R. A. (2007). The interoceptive Pavlovian stimulus effects of caffeine. Pharmacology, Biochemistry and Behavior, 86, 838-846.

National Research Council. (1996). Guide for the care and use of laboratory animals. Washington, DC: National Academy Press.

Olausson, P., Jentsch, J. D., \& Taylor, J. R. (2003). Repeated nicotine exposure enhances reward-related learning in the rat. Neuropsychopharmacology, 28, 1264-1271. 
Palmatier, M. I., \& Bevins, R. A. (2007). Facilitation by drug states does not depend on acquired excitatory strength. Behavioural Brain Research, 176, 292-301.

Palmatier, M. I., Evans-Martin, F. F., Hoffman, A., Caggiula, A. R., Chaudhri, N., Donny, E. C., et al. (2006). Dissociating the primary reinforcing and reinforcement-enhancing effects of nicotine using a rat self-administration paradigm with concurrently available drug and environmental reinforcers. Psychopharmacology, 184, 391-400.

Papke, R. L., Sanberg, P. R., \& Shytle, R. D. (2001). Analysis of mecamylamine stereoisomers on human nicotinic receptor subtypes. Journal of Pharmacology and Experimental Therapeutics, 297, 646-656.

Parrott, A. C. (2006). Nicotine psychobiology: How chronicdose prospective studies can illuminate some of the theoretical issues from acute-dose research. Psychopharmacology, 184, 567-576.

Parrott, A. C., \& Garnham, N. J. (1998). Comparative mood states and cognitive skills of cigarette smokers, deprived smokers, and non-smokers. Human Psychopharmacology, 13, 367-376.

Parrott, A. C., \& Kaye, F. J. (1999). Daily uplifts, hassles, stresses and cognitive failures: In cigarette smokers, abstaining smokers, and non-smokers. Behavioural Pharmacology, 10, 639-646.

Pavlov, I. P. (1927). Conditioned reflexes. London: Oxford University Press.

Payne, T. J., Schare, M. L., Levis, D. J., \& Colletti, G. (1991). Exposure to smoking-relavent cues: Effects on desire to smoke and topographical components of smoking behavior. Addictive Behaviors, 16, 467-479.

Pidoplichko, V. I., DeBiasi, M., Williams, J. T., \& Dani, J. A. (1997). Nicotine activates and desensitizes midbrain dopamine neurons. Nature, 390, 401-404.

Poulos, C. X., Hinson, R. E., \& Siegel, S. (1981). The role of Pavlovian processes in drug tolerance and dependence: Implications for treatment. Addictive Behaviors, 6, 205-211.

Rauhut, A. S., Dwoskin, L. P., \& Bardo, M. T. (2005). Tolerance does not develop to the decrease in nicotine self-administration produced by repeated bupropion administration. Nicotine E Tobacco Research, 7, 901-907.

Rauhut, A. S., Mullins, S. N., Dwoskin, L. P., \& Bardo, M. T. (2002). Reboxetine: Attenuation of intravenous nicotine self-administration in rats. The Journal of Pharmacology and Experimental Therapeutics, 303, 664-672.

Reichel, C. M., Linkugel, J. D., \& Bevins, R. A. (2007). Nicotine as a conditioned stimulus: Impact of attention deficit/hyperactivity disorder medication. Experimental and Clinical Psychopharmacology, 15, 501-509.

Reichel, C. M., Linkugel, J. D., \& Bevins, R. A. (2008). Bupropion differentially impacts acquisition of methamphetamine self-administration and sucrose-maintained behavior. Pharmacology, Biochemistry and Behavior, 89, 463-472.

Rescorla, R. A. (1997). Spontaneous recovery after Pavlovian conditioning with multiple outcomes. Animal Learning $\mathcal{E}$ Behavior, 25, 99-107.

Rescorla, R. A. (2004). Spontaneous recovery. Learning \& Memory, 11, 501-509.

Revell, A. D. (1988). Smoking and performance: A puff-by-puff analysis. Psychopharmacology, 96, 563-565.
Russell, M. A. (1989). Subjective and behavioural effects of nicotine in humans: Some sources of individual variation. Progress in Brain Research, 79, 289-302.

Servatius, R. J., Brennan, F. X., Beck, K. D., Beldowicz, D., \& CoyleDiNorcia, K. (2001). Stress facilitates acquisition of the classically conditioned eyeblink response at both long and short interstimulus intervals. Learning and Motivation, 32, 178-192.

Shiffman, S., Gwaltney, C. J., Balabanis, M. H., Liu, K. S., Paty, J. A., Kassel, J. D., et al. (2002). Immediate antecedents of cigarette smoking: An analysis from ecological momentary assessment. Journal of Abnormal Psychology, 111, 531-545.

Shoaib, M., \& Stolerman, I. P. (1992). MK801 attenuates behavioural adaptation to chronic nicotine administration in rats. British Journal of Pharmacology, 105, 514-515.

Simon, N. W., \& Setlow, B. (2006). Post-training amphetamine administration enhances memory consolidation in appetitive Pavlovian conditioning: Implications for drug addiction. Neurobiology of Learning and Memory, 86, 305-310.

Stolerman, I. P. (1999). Inter-species consistency in the behavioural pharmacology of nicotine dependence. Behavioural Pharmacology, 10, 559-580.

Stolerman, I. P., Garcha, H. S., Pratt, J. A., \& Kumar, R. (1984). Role of training dose in discrimination of nicotine and related compounds by rats. Psychopharmacology, 84, 413-419.

Swithers-Mulvey, S. E., \& Hall, W. G. (1992). Control of ingestion by oral habituation in rat pups. Behavioral Neuroscience, 106, 710-717.

Takada, K., Hagen, T. J., Cook, J. M., Goldberg, S. R., \& Katz, J. L. (1988). Discriminative stimulus effects of intravenous nicotine in squirrel monkeys. Pharmacology, Biochemistry, and Behavior, 30, 243-247.

Tiffany, S. T., Drobes, D. J., \& Cepeda-Benito, A. (1992). Contribution of associative and nonassociative processes to the development of morphine tolerance. Psychopharmacology, 109, 185-190.

Tomie, A., Hayden, M., \& Biehl, D. (1980). Effects of response elimination procedures upon the subsequent reacquisition of autoshaping. Animal Learning \& Behavior, 8, 237-244.

Ulloa, L. (2005). The vagus nerve and the nicotinic anti-inflammatory pathway. Nature Reviews Drug Discovery, 4, 673-684.

US Department of Health and Human Services. Healthy people 2010: Understanding and improving health. $2^{\text {nd }}$ Ed.Washington, DC: US Department of Health and Human Services.

Warburton, D. M., \& Arnall, C. (1994). Improvements in performance without nicotine withdrawal. Psychopharmacology, 115, 539-542.

Weeks, J. R. (1972). Long-term intravenous infusion. In: R. D.Myers (Ed.), Methods in psychobiology (pp. 155-168). New York: Academic Press.

Wilkinson, J. L., Murray, J. E., Li, C., Wiltgen, S. M., Penrod, R. D., Berg, S. A.et al., (2006). Interoceptive Pavlovian conditioning with nicotine as the conditional stimulus varies as function of number of conditioning trials and unpaired sucrose deliveries. Behavioural Pharmacology, 17, 161-172.

Wooltorton, J. R. A., Pidoplichko, V. I., Broide, R. S., \& Dani, J. A. (2003). Differential desensitization and distribution of nicotinic acetylcholine receptor subtypes in midbrain dopamine areas. The Journal of Neuroscience, 23, 3176-3185. 